\title{
The Effect of Lexical Glossing Types on Reading and Listening Skills of Iranian EFL Learners
}

\author{
Niloofar Fahimipour \\ English Department, Islamic Azad University, Najaf Abad Branch, Iran \\ Mahmood Hashemian \\ English Department, Shahrekord University, Shahrekord, Iran
}

\begin{abstract}
Knowing what factors influence, positively or negatively, the reading and listening ability of language learners is of crucial importance. Amid these factors the type of glossing can be named which number of studies on it, especially in our country, Iran is rare. The present study, therefore, aimed at investigating the lexical glossing impact on such skills as reading and listening comprehension of a group of Iranian EFL learners. To put it clearly, the study is, in fact, an attempt to ascertain if L1 or L2 lexical glossing may make any difference in their effectiveness on $L 2$ reading and listening comprehension processes. To achieve the intended purpose, 60 female students learning English as a foreign language in an English language school in Isfahan, Iran were randomly selected and were grouped into two intact classes. They were required to take two TOEFL tests: one as a pretest to ensure their homogeneity concerning language proficiency, and one to specify the impact of glossing on their listening and reading comprehension, respectively. Conducting a one-way analysis of variance (MANOVA) and two independent sample $t$ tests, the study revealed that first, there was a significant difference between the two groups receiving Persian and English glosses. Besides, the study indicated that the class receiving native language gloss (i.e., Persian lexical gloss) outperformed compared with the class getting the second language gloss (i.e., English gloss) in both reading and listening comprehension although this effect was more on the former than the latter one. The study may have some pedagogical implications in the realm of $\mathrm{L} 2$ research that the present researchers will point out throughout the paper.
\end{abstract}

Index Terms—glossing, listening skill, reading skill, Iranian EFL learners

\section{INTRODUCTION}

Vocabulary or lexicon can be considered as one the crucial facets of an L2. Its significance is to the extent that even some L2 researchers (e.g., Nagata, 1999; Sanaoui, 1996) make an equivalence between L2 learning process and knowing L2 words. Although someone may consider this claim an overstatement, the crucial role of L2 vocabulary should not be overlooked. Further, L2 researchers (e.g., Dufon \& Fong, 1994; Nagata, 1999) have mentioned that vocabulary knowledge is multi-faceted (Harley, 1996). Therefore, L2 classroom teachers need to take a more complete approach regarding vocabulary development in order to help L2 learners to access a higher level of L2 output (Sanaoui, 1996; Swain, 1996). The aforementioned researchers state three aspects for word difficulty: a) receptive versus productive vocabularies, b) breadth versus depth of vocabularies, and c) direct teaching versus contextual inferencing of vocabulary.

In order to improve vocabulary learning, different discussions (Hulstijn, Hollander, \& Greidanus, 1996; Jacobs, Dufon, \& Fong, 1994; Mondria, 2003; Nagata, 1999; Rott, 2007; Rott \& William, 2003; Watanabe, 1997; Yoshii, 2006) concerning the effectiveness of various reading text enhancement have been proposed. There is a general agreement on the topic that glosses utilization can improve L2 learners' vocabulary learning while reading. The aforesaid positive impacts of gloss in order to enhance vocabulary learning are due to several factors. First, as Hulstijn et al., 1996 puts it, in comparison to dictionary, gloss is more accessible and easier to use because it provides accurate meanings for words. Second and based on Nagata (1999), due to its bold-faced design, gloss can attract L2 learners' attention to L2 words; and therefore, support the notions of "consciousness-raising" and "input-enhancement". Carrying the least amount of interruption in reading process and providing the form-meaning connection, Gloss also helps to connect word forms to meanings (Rott \& William, 2003). Last but not least, glossing may persuade L2 learners to read back and forth. Thus, as Jacobs et al. (1994) mentions, it can trigger more lexical processing resulting in word retention.

One profitable line of enquiry might be the focus of attention on gloss types (Gettys, Imhof, \& Kautz, 2001; Grace, 1998, 2000; Nagata, 1999; Watanabe, 1997). In other words, a significant amount of attention has been paid to specifying what gloss types can make positive learning effects. Regarding this issue, various researchers (Hulstijn et al., 1996; Mondria, 2003; Rott, 2007; Rott \& William, 2003; Watanabe, 1997) have focused on the possible impact of gloss on L2 learners' decision-making process. The argument is that the use of gloss might deprive L2 learners of inferring that, in turn, it reduces the amount of processing. In order to activate L2 learners' processing through fostering learners' 
involvement, Hulstijn (1992) is in favor of providing multiple-choice meaning-inferred gloss rather than direct meaning-given gloss.

Besides, as to the progresses in glossing, some of the properties of advanced glossing (i.e. glossing in L2 not mother language) making it separated from traditional glossing formats originate from its different purposes. Hulstijn further adds that utilizing glossed texts as a basis for a complete language description can make a suitable place for such different type of information as phonetic, phonological, orthographical, prosodic, categorical, structural, relational, and semantic.

In addition, studies to compare the effectiveness of L1 and L2 glosses have led into mixed results. Some studies show no difference between the two types and others propose the superiority of one gloss type over the other type (Chen, 2002; Jacobs et al., 1994; Miyasako, 2002). Jacobs et al. (1994), for instance, compared L1 with L2 glosses among 85 English-speaking participants studying Spanish as an L2. A Spanish text was presented with 613 words under three conditions: 1) L1 (English) gloss, 2) L2 (Spanish) gloss, and 3) No gloss. After reading the text having 32 boldfaceglossed words, the researchers gave two vocabulary tests to participants: one immediately after the reading and the other four weeks later. The results regarding the immediate test indicated the superiority of gloss conditions (i.e., either L1 or L2) on no gloss condition. It is worth mentioning that the results did not state any significant difference between L1 and L2 glosses.

In order to demonstrate that the L2 group outperforms the no gloss group, Chen (2002) also examined L1 and L2 glosses of 85 college freshmen in Taiwan studying English as an L2. The participants were categorized into three groups: 1) L1 (Chinese) gloss, 2) L2 (English) gloss, and 3) no gloss. They were supposed to read a 193 word-English text with $20 \mathrm{~L} 2$ glossed words. The results indicated that the difference between L1 and L2 glosses was not significant. The other possibility supported by Chen (2002) was that the L2 gloss group needed a longer time for reading the text than the other group.

Also, in order to demonstrate the advantage of one gloss type over the other, Miyasako (2002) investigated the impact of multiple-choice and single glosses. The research design included six groups: 1) L2 (English) multiple-choice gloss, 2) L1 (Japanese) multiple-choice gloss, 3) L2 (English) single gloss, 4) L1 (Japanese) single gloss, 5) no gloss, and (6) control (no reading). The participants included 187 Japanese high school students, and they were supposed to read a 504-word text with 20 L2 words. Then, the researchers gave two vocabulary tests to students: one multiplechoice test immediately after reading and the other 18 days later. Miyasako found that the L2 gloss group outperformed the L1 gloss group significantly in the immediate test. However, the multiple-choice and single gloss types did not differ in their effectiveness on vocabulary learning. The other possibility was that the L2 glosses were in favor of the higher-proficiency level L2 learners, whereas the L1 glosses were more effective for the lower-proficiency ones.

Lastly, with regard to another aspect of L2 language, that is, the receptive skills, they have been looked into through different studies from different windows. Consequently, different results and implications have been proposed on them. As to the reading skill, reading is considered to be a multifaceted process that requires L2 learners to access prior knowledge of the world and how it operates in order to extract meaning from a text.

Many studies (e.g., Bowles, 2004; Davis, 1989; Lomicka, 1998) have been carried out on the effects of lexical glossing. However, the central focus of them have been on issues like the language of presented glosses, the place to present the glosses, and the kinds of glosses (i.e., multiple-choice glosses, monomial glosses, or no glosses). Majority of the aforementioned studies have been on the link between lexical glossing and reading comprehension, and little research has been conducted on the relationship between lexical glossing and listening comprehension. Therefore, the present study aims to investigate the effect of lexical glossing on reading and listening comprehension of a group of Iranian EFL learners and tries to fill the gap as far as possible. Besides, such studies in EFL contexts, including the context of the present study (i.e., Iran), are very small. Therefore, it can be said that the necessity for doing studies like the current one is strongly felt.

Furthermore, despite the rich literature on the effectiveness of different gloss types, little research has comparatively focused on the effects of type of gloss and receptive skills. This fact is supported by the claim of presenting a good way for vocabulary learning to take place through reading and listening skills. According to Mondria (2003), this process can be effected through rich contextual clue, learners' knowledge of the context words, and learners' skills. Besides, due to miscellaneous findings concerning the effects of gloss on different aspects of language, it seems to be a necessity to re-examine the effects of gloss on learners' different aspects especially reading and listening abilities.

All in all, having considered the abovementioned remarks and also the existing problem(s), the present study is, in fact, an attempt to address the following research questions:

1. On which of the dependent variables (i.e., reading and listening skills) is the effect of L1 or L2 lexical glossing more salient?

2. Do L1 or L2 lexical glossing differ in their effectiveness on Iranian reading comprehension?

3. Do L1 or L2 lexical glossing differ in their effectiveness on Iranian listening comprehension?

\section{Methodology}

\section{A. Participants}


In order to perform the study, two classes of female students $(N=60)$ learning English as an L2 in an English language institute in Isfahan served as the participants, whose age ranged from 17 to 26 and took part in advanced classes in the institute. These two intact classes were randomly selected as the study groups (i.e., Group 1 for listening and Group 2 for reading). The participants of the study were pretested for their proficiency by taking the TOEFL test before launching the study.

\section{B. Materials}

Altogether, two main instruments were employed to gather the data. First, to begin the study and to gauge the participants' same level of proficiency, they were given a reduced form of the TOEFL test that contained listening, reading, and vocabulary sections. The results of the vocabulary section of the test were also used to see whether the participants enjoyed similar knowledge of vocabulary at the beginning of the study or not.

Second, another test of TOEFL, consisting of the reading and listening sections accompanied by glosses in Persian and English were used to specify the impact of type of glossing on the two skills. The reading test consisted of 40 items in the form of multiple-choice, and the listening test included 25 multiple-choice items. The tests contained some reading and listening comprehension passages accompanied by their respective items extracted from a few TOEFL tests, and some reading and listening comprehension items were also constructed by the researcher for the texts that were not originally followed by such items. It is worth mentioning that the reliability of the reading and listening tests was also tested via Cronbach's Alpha turning out to be .72 and .76 , respectively. Also, regarding the validity of the tests, they were submitted to two experts in the field, and they unanimously agreed on the content.

\section{Procedure}

At the beginning of the study, the simplified version of the TOEFL test (Cronbach's Alpha $=.79$ ) was administered to determine that the participants enjoyed a similar level of proficiency, and that their knowledge of vocabulary was also the same. The test was carried out in the two groups as a pretest to determine their equality in vocabulary, reading, and listening comprehension ability.

Then, in another session in one of the classes (i.e., Class 2), the participants received the Persian vocabulary glosses when they took the listening and reading comprehension tests, and in the other class (i.e., Class 1) they received the English vocabulary glosses while taking the reading and listening tests.

\section{RESULTS AND DISCUSSION}

Prior to the main study analysis and for the sake of ensuring the homogeneity of the two groups in terms of their performance, a pretest was administered to both groups. Table 4.1 reveals the descriptive results of the analysis. As the table shows, the mean score in class 1 is 10.43 and in class 2 is 11.04, respectively. Although slightly different, the real difference of the two mean scores is very small, nearly .5 scale points. Therefore, the two classes are homogeneous regarding their performance.

TABLE 1.

DESCRIPTIVE STATISTICS IN PRETEST

\begin{tabular}{|ll|l|l|l|l|}
\hline & Codes & $N$ & Mean & Std. Deviation & Std. Error Mean \\
\hline \multirow{2}{*}{ Pretest } & Class 1 & 30 & 10.43 & 2.11 & .36 \\
& Class 2 & 30 & 11.04 & 2.26 & .40 \\
\hline
\end{tabular}

Having ensured the homogeneity of two classes, as a matter of comparing the participants' performance and analyzing the mean differences between groups in reading and listening tests when English and Persian glossing were provided, a one-way MANOVA was carried out. Thus, the aforesaid comprehension skills were identified as the dependent variables and concerning two levels of independent variable, the type of glossing (i.e., English and Persian) was identified. As to the multivariate normality, the researchers measured mahalanobis distances (Tabachnick \& Fidell, 2007). The related data has been depicted in Table 2:

TABLE 2.

RESIDUAL STATISTICS

\begin{tabular}{|l|l|l|l|l|l|}
\hline & Minimum & Maximum & Mean & Std. Deviation & $N$ \\
\hline Stud. Residual & -2.088 & 1.707 & -.001 & 1.008 & 60 \\
Mahal. Distance & .508 & 15.767 & 2.962 & 3.071 & 60 \\
Cook's Distance & .000 & .267 & .014 & .031 & 60 \\
Centered Leverage Value & .006 & .225 & .037 & .039 & 60 \\
\hline
\end{tabular}

For determining the number of outliers, the mahalanobis distance value was compared against a critical value indicated by Pallant (2007, p. 280) by applying a chi-square critical value table as below: 
TABLE 3.

CRITICAL VAlues For MEASURING MaHalanobis Distance VAlues

\begin{tabular}{|l|l|l|l|l|l|}
\hline $\begin{array}{l}\text { Number of Dependent } \\
\text { Variables }\end{array}$ & Critical Value & $\begin{array}{l}\text { Number of Dependent } \\
\text { Variables }\end{array}$ & Critical Value & $\begin{array}{l}\text { Number of } \\
\text { Dependent Variables }\end{array}$ & Critical Value \\
\hline 2 & 13.82 & 5 & 20.52 & 8 & 26.13 \\
\hline 3 & 16.27 & 6 & 22.46 & 9 & 27.88 \\
\hline 4 & 18.47 & 7 & 24.32 & 10 & 29.59 \\
\hline
\end{tabular}

As Pallant (2007) mentions, outliers are the individuals whose mah-1 grades go far beyond these critical values. According to Table 4.2, mahalanobis distance value is 15.76. Then, the present researchers compare it with the recommended critical value in Table 3 . In the current study, the number of the dependent variables is two. Thus, the critical value for that is 13.82 .

Taking the previous points into account, the mahalanobis distance value (15.76) is larger than the critical value (13.82) indicating the presence of multivariate outliers. Upon searching the data file, just one case exceeded the critical value of 13.82, indicating one multivariate outlier. Due to the presence of only one person, the present researchers decided to keep this case. Later on, the assumption of linearity was checked indicating a straight line relationship between dependent variables. It confirmed the assumption of linearity.

Regarding the assumption of homogeneity of variance-covariance matrices, Box's Test of Equality of Covariance Matrices was investigated. The Box's M Sig. value is .116 that is larger than .001 indicating that this assumption is not violated:

TABLE 4.

BOX'S TEST OF EQUALITY

\begin{tabular}{|l|l|}
\multicolumn{2}{c}{ BOX's TEST OF EQUALITY } \\
\hline Box's M & 10.658 \\
$F$ & 1.701 \\
Df1 & 6 \\
Df2 & $3.954 \mathrm{E} 4$ \\
Sig. & .116 \\
\hline
\end{tabular}

Measuring equal variances, the Levene's Test of Equality of Error Variance was studied:

TABLE 5.

LEVENE'S TEST OF EQUALITY OF ERROR VARIANCES

\begin{tabular}{|l|l|l|l|l|}
\hline & $F$ & $d f 1$ & $d f 2$ & Sig. \\
\hline Reading & 1.486 & 1 & 58 & .226 \\
Listening & .198 & 1 & 58 & .658 \\
\hline
\end{tabular}

Because all the Sig. values are larger than .05, the assumption of the equality of variance is confirmed. Therefore, there is a normal distribution among all the three groups.

To find statistically significant differences among groups, the researchers studied Wilk's Lambda in the multivariate tests of significance:

TABLE 6.

Multivariate TeSTS ${ }^{\mathrm{B}}$

\begin{tabular}{|l|l|l|l|l|l|l|l|}
\hline & Effect & Value & $F$ & Hypothesis $d f$ & Error $d f$ & Sig. & Partial Eta Squared \\
\hline & Pillai's Trace & .989 & $2.229 \mathrm{E} 3^{\mathrm{a}}$ & 3.000 & 76.000 & .000 & .989 \\
\hline & Wilks' Lambda & .011 & $2.229 \mathrm{E} 3^{\mathrm{a}}$ & 3.000 & 76.000 & .000 & .989 \\
\hline & Hotelling's Trace & 87.979 & $2.229 \mathrm{E}^{\mathrm{a}}$ & 3.000 & 76.000 & .000 & .989 \\
\hline & Roy's Largest Root & 87.979 & $2.229 \mathrm{E} 3^{\mathrm{a}}$ & 3.000 & 76.000 & .000 & .989 \\
\hline Type of Glossing & Pillai's Trace & .158 & $4.746^{\mathrm{a}}$ & 3.000 & 76.000 & .004 & .158 \\
\hline & Wilks' Lambda & .842 & $4.746^{\mathrm{a}}$ & 3.000 & 76.000 & .004 & .158 \\
\hline & Hotelling's Trace & .187 & $4.746^{\mathrm{a}}$ & 3.000 & 76.000 & .004 & .158 \\
\hline & Roy's Largest Root & .187 & $4.746^{\mathrm{a}}$ & 3.000 & 76.000 & .004 & .158 \\
\hline
\end{tabular}

b. Design: Intercept + Type of Glossing

In the row indicating the name for the independent variable (type of glossing), the value for Wilk $\square \mathrm{s}$ Lambda is .842 and the significant value is .004 . Because it is less than .05 , there is a significant difference between two classes presented different types of glossing (i.e., English and Persian) regarding their reading and listening comprehension.

In the next stage, the Test of Between-Subject Effects output box is studied. In order to decrease the chance of a type 1 error, Bonferroni adjustment is applied (Pallant, 2007). Therefore, the original alpha level of .05 was divided by the number of analyses intended.

Due to the presence of two dependent variables (i.e., reading and listening comprehension), .05 is divided by 2 , providing a new alpha level of .025 . Then, Test of Between-Subjects Effects box is studied. 
Upon looking at Table 7, the Sig. column for the two dependent variables indicated a significant value less than the cut-off point (with the Sig. values of .004 and .002). Thus, there is a significant difference between two groups presented English and Persian glossing was on both kinds of reading and listening comprehension:

TABLE 7

TESTS OF BETWEEN-SUBJECT EFFECTS

\begin{tabular}{|l|l|l|l|l|l|l|l|}
\hline \multirow{2}{*}{ Source } & $\begin{array}{l}\text { Dependent } \\
\text { Variable }\end{array}$ & $\begin{array}{l}\text { Type III Sum of } \\
\text { Squares }\end{array}$ & $\begin{array}{l}\text { Mean } \\
\text { Square }\end{array}$ & $F$ & Sig. & Partial Eta Squared \\
\hline Corrected Model & Reading & $63.112^{\mathrm{a}}$ & 1 & 63.112 & 8.794 & .004 & .101 \\
& Listening & $91.010^{\mathrm{b}}$ & 1 & 91.010 & 10.013 & .002 & .114 \\
\hline Intercept & Reading & 6489.212 & 1 & 6489.212 & 904.217 & .000 & .921 \\
& Listening & 7006.010 & 1 & 7006.010 & 770.785 & .000 & .908 \\
\hline Type of Glossing & Reading & 63.112 & 1 & 63.112 & 8.794 & .004 & .124 \\
& Listening & 91.010 & 1 & 91.010 & 10.013 & .002 & .111 \\
\hline Total & Reading & 7049.000 & 80 & & & & \\
\hline
\end{tabular}

a. R Squared = .101 (Adjusted R Squared $=.090)$

b. R Squared $=.114$ (Adjusted R Squared $=.102)$

c. R Squared $=.079($ Adjusted R Squared $=.067)$

Therefore, the first null hypothesis below is rejected:

- $\mathrm{H}_{01}$ : Glossing effect is equal on the two dependent variables of the study (i.e., reading and listening skills).

The significance of the impact of type of glossing on reading and listening comprehension was also evaluated by applying the effect size statistics. Partial Eta Squared was used. Applying the guidelines $(.01=$ small, .06 = moderate, $.14=$ large) offered by Cohen $(1988$, p. 284-287), the value of .124 for reading comprehension is somehow a large effect and shows $12.4 \%$ of variance explained by the type of glossing. The Partial Eta Squared for listening comprehension is .111 that is somehow a large effect and explains $11.1 \%$ of variance by type of glossing.

Although it was concluded that the two classes with different types of glossing differed concerning their reading and listening comprehension, it is not obvious which group had the higher score. To find out this, the Estimated Marginal Means Table should be studied. Table 8 shows the descriptive statistics of the two groups across the aforesaid kinds of comprehension tests:

TABLE 8

ESTIMATED MARGINAL MEANS

\begin{tabular}{|ll|l|l|l|}
\hline \multirow{2}{*}{$\begin{array}{l}\text { Dependent } \\
\text { Variables }\end{array}$} & & \multicolumn{2}{l|}{$95 \%$ Confidence Interval } \\
\cline { 4 - 5 } & Type of Glossing & Mean & Lower Bound & Upper Bound \\
\hline Reading & English (class 1) & 29.23 & 26.355 & 32.063 \\
& Persian (class 2) & 33.33 & 30.056 & 35.033 \\
\hline Listening & English (class 1) & 18.47 & 15.672 & 21.382 \\
& Persian (class 2) & 19.13 & 16.633 & 22.244 \\
\hline
\end{tabular}

In the reading comprehension, the mean score in class 1 is 29.23 and in class 2 is 33.33 , respectively, which shows a statistically significant difference. In fact, there is a significant difference between two classes based on the fact that Persian glossing can produce better results in reading comprehension. This fact was further supported through doing an independent sample $t$ test as presented bellow:

TABLE 9

INDEPENDENT SAMPLE T TEST FOR GLOSSING IMPACT ON READING

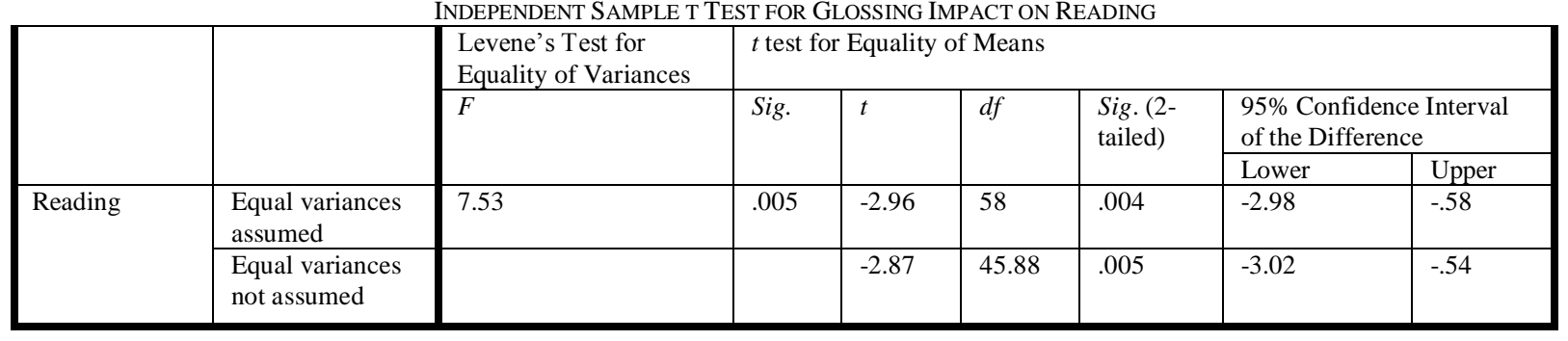


Through looking at the output box giving the results of Levene's test for equality of variances, the significant level for Levene's test was .005 . Because it was less than the cut-off .05, equal variance was not assumed. By referring to the column labeled sig. (2-tailed), the value for unequal variance was .005. Because it was less that .05, there was a significant difference in the mean scores of two groups and their performance on reading comprehension. Therefore, the second null hypothesis is not confirmed too:

- $\mathrm{H}_{02}$ : L1 and L2 lexical glossing do not differ in their influence on Iranian learners' reading comprehension.

Also, in the listening comprehension, the mean score in class 1 is 18.47 and in class 2 is 19.13 . To put it plainly, there is a significant difference between two classes based on the fact that Persian glossing can produce better results in listening comprehension. This fact was further supported through doing an independent sample $t$ test as presented here:

TABLE 10

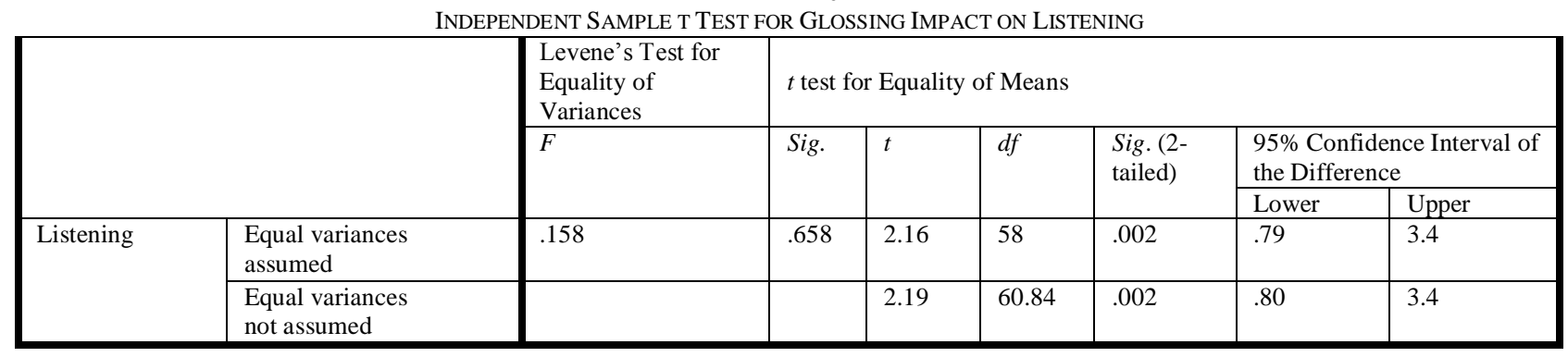

As Table 10 reveals, because the sig. value (.658) was larger than the cut-off .05 , equal variance was assumed. Therefore, the sig. (2-tailed) for equal variance was .002. Because it was less than .05, there is a significant difference regarding the mean scores of two groups and their performance on listening comprehension. Thus, the third null hypothesis below is also rejected:

- $\mathrm{H}_{03}$ : L1 and L2 lexical glossing do not differ in their influence on Iranian learners' listening comprehension.

\section{CONCLUSION}

Reviewing the related literature, lexical glossing as an aspect of different L2 enquiries (e.g., Grace, 1998, 2000; Nagata, 1999; Taylor, 2006; Watanabe, 1997) have brought mixed and conflicting results. As such, the aim of this study was to study the impact of L1 and L2 lexical glossing on L2 learners' reading and listening comprehension. In fact, the aim was to have an investigation into defining the role of L1 and L2 lexical glossing on reading and listening comprehension and to draw on the findings in our teaching career, and accordingly, to improve L2 learners' reading and listening comprehension.

According to the results of the reading test, there was a significant difference regarding the mean scores of class 1 and 2. Thus, the difference between these two groups may be attributed to the type of lexical glossing in a way that the participants provided Persian glossing performed better in reading comprehension. Also, the impact of Persian glossing was significant based on the mean score in listening comprehension. In other words, the findings of this study illustrate that although the effect of Persian glossing was more than English one in reading comprehension, it had also a slight effect on listening comprehension too. Therefore, all of the three null hypotheses of the current study were rejected. Regarding the positive influence of gloss, there has been a shift from gloss effects to gloss types (Gettys, Imhof, \& Kautz, 2001; Grace, 1998, 2000; Nagata, 1999; Watanabe, 1997).

The findings are consistent with the one by Hulstijn, Hollander, and Greidanus, (1996), Jacobs, Dufon, and Fong (1994), Mondria (2003), Rott (2007) who explain that the possibility of the application of glosses is beneficial for L2 learners' vocabulary learning while reading because the definition is easily available in the text.

Besides, the findings support Davis (1989) and Jacobs et al. (1994) who tend to be in favor of using glossing in L2 reading. This could be explained by the fact that the students who can use glosses before reading or during the reading process recalled the text more than others did.

These explanations go in line with the view held by Jacobs et al. (1994) explaining that L1 and L2 gloss conditions could make better results than the no gloss condition. Likewise, in the present research, the participants provided Persian glossing performed better in reading comprehension.

In addition, the results of this study are against the claims of recent researchers like Bell and LeBlanc (2000) who claim that although the participants showed a preference for using glosses in L1, they did not show any difference between the English and Spanish gloss groups. Thus, the language of glosses was not so much important.

The findings are also in contrast to the one by Chen's (2002) study investigating the same matter among Taiwanese participants studying English as an L2. The results indicated that the difference between the L1 and the L2 gloss groups was not statistically significant.

In sum, the findings stand in total contrast to Johnson (1982) and Jacobs et al. (1994) who stated that glossing may not enhance a global comprehension of the text. As with related studies previously done on the same issue, the more the 
author searched the less she could find any study specifically dealing with the relationship between glossing and listening skill. This lack of study highlights more than ever the significance of the current study.

Based on the current study, glossing occupies a dominant position in 12 learners' reading and listening comprehension. The present study was, to some extent, guided by the design exploited by Jacobs et al. (1994) to investigate the effect of L1 and L2 lexical glossing on reading and listening comprehension with some modifications and deletions.

The present research methodology can be counted as an attempt to investigate reading and listening comprehension through two types of glossing on the part of L2 learners. In brief, the results of the study indicate that type of lexical glossing is a source of systematic variance in receptive skills. To put it in a nutshell, to the present researcher, the study on the role of L1 and L2 lexical glossing in receptive skills would bring insights and significance for future studies.

The positive effects of gloss on fostering vocabulary learning can be attributed to several factors. First, gloss is more accessible and easier to use than dictionary in that it provides accurate meanings for words that might be guessed incorrectly (Hulstijn et al., 1996). Second, with its bold-faced design, gloss salience can draw L2 learners' attention to L2 words, supporting the notion of "consciousness-raising" and "input-enhancement" (Nagata, 1999).

Also, HeeKo (2005) claims four advantages in using glosses. Firstly, glosses can get across new L2 words so accurately that prevent incorrect guessing. Secondly, they can decrease interruptions while reading is in process. As glosses provide definitions for low frequency L2 words, L2 learners would no more require checking or looking them up. Thirdly, glosses can make a meaningful relation between prior knowledge and new information in text. Finally, glosses would allow for greater autonomy on the part of L2 learners.

\section{REFERENCES}

[1] Bell, F. L. \& LeBlanc, L. B. (2000). The language of glosses in L2 reading on computer: Learners' preferences. Hispania 83.2, 274-285.

[2] Bowles, M. A. (2004). L2 glossing: To CALL or not CALL. Hispania 87.3, 541-552.

[3] Chen, H. (2002). Investigating the effects of L1 and L2 glosses on foreign language reading comprehension and [4] vocabulary retention. Paper presented at the annual meeting of the Computer-Assisted Language Instruction Consortium, Davis, CA.

[4] Davis, J. N. (1989). Facilitating effects of marginal glosses on foreign language reading. Modern Language Journal 73.1, 41-48.

[5] Dufon, P. \& Fong, C. H. (1994). L1 and L2 vocabulary glosses in L2 reading passages: Their effectiveness for increasing comprehension and vocabulary knowledge. Journal of Research in Reading 17.1, 19-28.

[6] Elley, W. (1989).Vocabulary acquisition from listening to stories. Reading Research Quarterly 19, 68-83.

[7] Ellis, R. (1999). Second language acquisition. Shanghai: Foreign Language Education Press.

[8] Gettys, S., Imhof, L. A. \& Kautz, J. O. (2001). Computer-assisted reading: The effect of glossing format on comprehension and vocabulary retention. Foreign Language Annals 34.2, 91-106.

[9] Grace, C. (1998). Retention of word meanings inferred from context and sentence-level translations: Implications for the design of beginning-level CALL software. The Modern Language Journal 82.4, 533-544.

[10] Grace, C. (2000). Gender differences: Vocabulary retention and access to translations for beginning language learners in CALL. The Modern Language Journal 84.2, 214-24.

[11] Harley, B. (1996). Introduction: Vocabulary learning and teaching in a second language. The Canadian Modern Language Review 53.1, 3-12.

[12] HeeKo, M. (2005). Glosses, comprehension, and strategy use. Reading in a Foreign Language 17, 180- 195.

[13] Hulstijn, J. H. (1992). Retention of inferred and given word meanings: Experiments in incidental vocabulary learning. In P. Arnaud \& H. Bejoint (eds.), Vocabulary and applied linguistics. London: Macmillan, 43-47.

[14] Hulstijn, J. H. \& Laufer, B. (2001). Some empirical evidence for the involvement load hypothesis in vocabulary acquisition. Language Learning 51.3, 539-558.

[15] Hulstijn, J. H., Hollander, M. \& Greidanus, T. (1996). Incidental vocabulary learning by advanced foreign language students: The influence of marginal glosses, dictionary use and the reoccurrence of unknown words. The Modern Language Journal 80 , $110-132$.

[16] Jacobs, G. M., Dufon, P. \& Hong, F. C. (1994). L1 and L2 vocabulary glosses in L2 reading passages: Their effectiveness for increasing comprehension and vocabulary knowledge. Journal of Research in Reading 17.1, 19-28.

[17] Jones, L. C. \& Plass, J. L. (2002).Supporting listening comprehension and vocabulary acquisition in French with multimedia annotations. The Modern Language Journal 86, 546-561.

[18] Johnson, P. (1982). Effects on reading comprehension of building background knowledge. TESOL Quarterly 16.4, 503-516.

[19] Kost, C. R., Foss, P. \& Lenzini, J. (2008).Textual and pictorial glosses: Effectiveness on incidental vocabulary growth when reading in a foreign language. Foreign Language Annals 32, 89-97.

[20] Laufer, B. (2001). Reading, word-focused activities and incidental vocabulary acquisition in a second language. Prospect 16.3, 56-69.

[21] Laufer, B. \& Hulstijn, J. (2001). Incidental vocabulary acquisition in second language: The construct of task induced involvement. Applied Linguistics 22.1, 88-99.

[22] Lomicka, L. L. (1998). To gloss or not to gloss: An investigation of reading comprehension online. Language Learning \& Technology 1.2, 41-50.

[23] Miyasako, J. (2002). L1 and L2 glosses: Their effects of incidental vocabulary learning. Language, Learning \& Technology 5.2, $110-120$. 
[24] Mondria, J. A. (2003). The effects of inferring, verifying, and memorizing on the retention of L2 word meanings: An experimental comparison of the meaning-inferred method and the meaning-given method. Studies in Second Language Acquisition 25.4, 473-499.

[25] Muoz, C. (2000). Bilingualism and trilingualism in school students in Catalonia. In Cenoz \& U. Jessner (eds.), English in Europe: The acquisition of a third language. Clevendon: Multilingual Matters, 157-178.

[26] Nagata, N. (1999). The effectiveness of computer-assisted interactive glosses. Foreign Language Annals 32.4, 469-479.

[27] Ortega, L. (2003). Syntactic complexity measures and their relationship to L2 proficiency: A research synthesis of college-level L2 writing. Applied Linguistics 24, 492-518.

[28] Pallant, J. (2007). SPSS survival manual: A step by step guide to data analysis using SPSS for windows ( $3^{\text {rd }}$ edn.). England: Open University Press.

[29] Plass, J. L., Chun, D. M., Mayer, R. E. \& Leutner, D. (1998). Supporting visual and verbal learning preferences in a second language multimedia learning environment. Journal of Educational Psychology 90, 25-36.

[30] Robinson, P. (1995). Attention, memory and the noticing hypothesis. Language Learning 45.2, 283-331.

[31] Rott, S. (2007). The effect of frequency of input-enhancements on word learning and text comprehension. Language Learning 57, 165-199.

[32] Rott, S. \& Williams, J. (2003). Making form-meaning connections while reading: A qualitative analysis of word processing. Reading in a Foreign Language 15.1, 89-90.

[33] Salomon, G. (1983). The differential investment of mental effort in learning from different sources. Educational Psychologist $18.1,42-50$.

[34] Sanaoui, R. (1996). Processes of vocabulary instruction in 10 French as a second language classrooms. The Canadian Modern Language Review 52.2, 179-199.

[35] Schmidt, R. (1990). The role of consciousness in second language learning. Applied Linguistics 11, 129-158.

[36] Schmidt, R. (2001). Attention. In P. Robinson (ed.), Cognition and second language instruction. Cambridge: Cambridge University Press, 3-32.

[37] Swain, M. (1996). Integrating language and content in immersion classrooms: Research prospectives. The Canadian Modern Language Review 52.4, 529-548.

[38] Tabachnick, B. G. \& Fidell, L. S. (2007). Using multivariate statistics (5 ${ }^{\text {th }}$ edn.). Boston: Pearson Education.

[39] Taylor, A. (2006). The effects of CALL versus traditional L1 glosses on L2 reading comprehension. CALICO Journal 23.2, 309-318.

[40] VanPatten, B. (1990). Attending to form and content in the input: An experiment in consciousness. Studies in Second Language Acquisition 12, 287-301.

[41] Watanabe, Y. (1997). Input, intake, and retention: Effects of increased processing on incidental learning of foreign language vocabulary. Studies in Second Language Acquisition 19.3, 287-307.

[42] Yoshii, M. (2006). L1 and L2 glosses: Their effects on incidental vocabulary learning. Language Learning and Technology $3.10,85-101$.

Niloofar Fahimipour got her B.A. in English Translation from Islamic Azad University, Shahreza Branch and her M.A. in TEFL from Islamic Azad University, Najaf Abad Branch. Her areas of interest include SLA, sociolinguistics, and cognitive linguistics. And, she has been teaching English at various language institutes for more than five years.

Mahmood Hashemian is an assistant professor at Shahrekord University. His area of research includes cognitive-semantic linguistics, sociolinguistics, and applied linguistics. He has published articles in academic journals such as JTLS, IJAL, IJLS, JALS, Linguistik Online, JLTR, TPLS, Iranian EFL Journal, IJEL, and International Journal of Social Sciences. Also, he has given lectures in several national and international conferences such as TELLSI (4, 7, 8, 9, \& 10), LDP2010/ LDP2013 (Ahvaz, Iran), ELT in the Islamic World (Tehran, Iran), 2nd International Language Conference 2011 (Malaysia), the 1st Thammasat ELT International Conference: Voices in ELT (Thailand), 1st International Akdeniz Language Studies Conference 2012 (Turkey), and 1st Conference on Language Learning \& Teaching: An Interdisciplinary Approach (Mashhad, Iran). 